\title{
Cholesterol changes the fatty acid composition of rat enterocytes
}

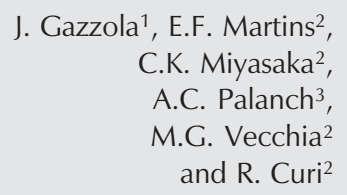

\author{
${ }^{1}$ Departamento de Ciências da Saúde, Universidade de ljuí, ljuí, RS, Brasil \\ ${ }^{2}$ Departamento de Fisiologia e Biofísica, Instituto de Ciências Biomédicas, \\ Universidade de São Paulo, São Paulo, SP, Brasil \\ ${ }^{3}$ Faculdade de Ciências da Vida, Universidade Metodista de Piracicaba, \\ Piracicaba, SP, Brasil
}

\section{Correspondence \\ C.K. Miyasaka \\ Departamento de Fisiologia e \\ Biofísica, ICB, USP \\ Av. Prof. Lineu Prestes, 1524 \\ 05508-900 São Paulo, SP \\ Brasil \\ Fax: +55-11-3091-7285 \\ E-mail: celio@fisio.icb.usp.br}

Research supported by FAPESP, CNPq, PRONEX, and CAPES.

Received July 3, 2002

Accepted November 7, 2002

\begin{abstract}
The effect of free cholesterol on the fatty acid composition and growth of rat fetal enterocytes was investigated in the absence and presence of $10 \%(\mathrm{v} / \mathrm{v})$ fetal calf serum. Cholesterol caused a significant reduction of cell number after 6 and $12 \mathrm{~h}$ in culture. The fatty acid composition of enterocytes cultured in the presence of serum was also changed by the presence of $20 \mu \mathrm{M}$ cholesterol. The fatty acid profile was determined by HPLC using fluorescence detection ( $325 \mathrm{~nm}$ excitation and $395 \mathrm{~nm}$ emission). Cholesterol $(20 \mu \mathrm{M})$ increased the proportion (given in percentage of the total fatty acids) of the following fatty acids in cultured cells: lauric (by $42 \%$ ), oleic (by $34 \%$ ), linoleic (by $44 \%$ ) and $\gamma$-linolenic (by 20\%) acids and reduced the proportion of palmitic (by $12 \%$ ), stearic (by $20 \%$ ), arachidonic (by $21 \%$ ) and docosahexaenoic (by $44 \%$ ) acids. In addition to modifying the content of individual fatty acids, cholesterol increased the polyunsaturated/saturated fatty acid ratio from 0.48 to 0.67 and the unsaturation index from 67.12 to 75.30 . This is the first evidence that cholesterol modifies fatty acid composition possibly via de novo fatty acid synthesis and desaturation.
\end{abstract}

Key words

- Enterocytes

- Cholesterol

- Fatty acid composition

- Cell proliferation
Cholesterol is a water-insoluble molecule and its intestinal absorption is very complex. In addition to diet, there are two endogenous sources of cholesterol: biliary cholesterol, which is always unesterified, and intestinal epithelial sloughing. Cholesterol absorption requires emulsification, hydrolysis of the ester bond (when esterified) by a specific pancreatic esterase, micellar solubilization, absorption in the proximal jejunum, reesterification within the intestinal cells, and transport to the lymph in the chylomicrons (1). The intestine, however, has a limited capacity to absorb cholesterol. The absorption of dietary cholesterol ranges from 40 to $60 \%$ independent of the amount ingested up to $600 \mathrm{mg}$ /day (2). The absolute amount of cholesterol absorbed increases in parallel with intake within the normal range (3). Therefore, a significant proportion of dietary cholesterol remains in the intestinal lumen to be excreted (4).

Cholesterol and fatty acids are primary components of cell membranes. Growing cells synthesize both cholesterol and fatty acids according to their growth demands (5). 
Recent evidence suggests that the synthesis of cholesterol, fatty acids and triglycerides is controlled by a common family of transcription factors designated sterol regulatory element-binding proteins (SREBP) (6). SREBP directly activate the expression of more than 30 genes dedicated to the synthesis and uptake of cholesterol, fatty acids, triglycerides, and phospholipids $(7,8)$. When the cholesterol content of cells increases, SREBP lose their ability to bind DNA and the transcription of target genes ceases. Cholesterol acting through SREBP activates the expression of several genes of the pathways of fatty acid and triglyceride synthesis such as fatty acid synthase and glycerol-3-phosphate acyltransferase. In addition, this sterol raises the expression of long-chain fatty acyl elongase and stearoyl CoA desaturase. These observations raise the possibility that cholesterol may be able to change the fatty acid composition of the cells.

These considerations and the fact that SREBP has been reported to be present in the intestine (9) led us to investigate the effect of free cholesterol on the fatty acid composition of rat fetal enterocytes. Concomitantly, the effect of cholesterol on enterocyte growth was also evaluated. The experiments were performed with and without fetal calf serum (FCS) in the media. The latter condition mimics the luminal side of the intestinal epithelium.

HF12 medium, DMEM, streptomycin and penicillin were obtained from Invitrogen (New York, NY, USA). DMSO, collagenase type IA, hyaluronidase, and cholesterol were purchased from Sigma (St. Louis, MO, USA). FCS was from Cutilab (Campinas, SP, Brazil) and trypsin was from the Adolfo Lutz Institute (São Paulo, SP, Brazil).

Male and female Wistar rats (3-4 months) obtained from the Department of Physiology and Biophysics, Institute of Biomedical Sciences, University of São Paulo, were maintained ( 3 females and 1 male) on a 12-h light/ dark cycle for 7 days. Pregnant female rats were housed in separate cages until the 20th day of pregnancy when they were killed by cervical dislocation, and the fetuses were collected after abdominal incision.

For the isolation and culture of enterocytes from rat fetuses, a modified protocol of the method described by Fukamachi (10) and Evans et al. (11) was used. Fetuses were washed with $70 \%$ alcohol. The small intestine was then dissected out and washed in Hank's balanced salt solution (HBSS) at $37^{\circ} \mathrm{C}$. Mesenteric tissue was removed and the intestine was opened laterally under a light microscope. The intestinal mucosa was treated with collagenase type IA $(458 \mathrm{U} / \mathrm{ml})$ and hyaluronidase $(320 \mathrm{U} / \mathrm{ml})$ in HBSS, at $37^{\circ} \mathrm{C}$ for $60 \mathrm{~min}$ in a shaker bath and the preparation was centrifuged at $1,200 \mathrm{~g}$ for 5 $\min$ at $4^{\circ} \mathrm{C}$. The pellet was resuspended in sterile HF12 medium by repeated pipetting using a Pasteur pipette. The cells were decanted in 50-ml polycarbonate tubes and centrifuged for periods of up to $10 \mathrm{~min}$. Cells were then cultured in $\mathrm{HF} 12$ medium at $37^{\circ} \mathrm{C}$ in an atmosphere of $5 \% \mathrm{CO}_{2}$ and $95 \%$ air. Cells were diluted in medium without FCS or in medium containing $10 \% \mathrm{FCS}$ to achieve a final concentration of $1.0 \times 10^{5}$ cells $/ \mathrm{ml}$. Cells were plated for the periods indicated above in 24-well plates and maintained at $37^{\circ} \mathrm{C}$ in an atmosphere of $5 \% \mathrm{CO}_{2}$ and $95 \%$ air. Cells were removed from the plates by gentle scraping and their total number and viability index were determined with a Neubauer chamber using $0.1 \%$ Trypan blue dye solution in saline.

Before addition to the medium, cholesterol was solubilized in ethanol. For the control, the same volume of ethanol was added at a final percentage which was always less than $0.5 \%$. Enterocyte growth curves were constructed in the presence and absence of FCS after 3, 6, 12, 24, 48 and $72 \mathrm{~h}$. The effect of cholesterol on cell growth in the presence and absence of FCS was tested at $20 \mu \mathrm{M}$ after 6 and $12 \mathrm{~h}$ in culture. Previous experiments using different concentrations and flow 
cytometry analysis established that $20 \mu \mathrm{M}$ cholesterol does not cause necrosis or apoptosis of enterocytes.

The effect of $20 \mu \mathrm{M}$ cholesterol on fatty acid composition was evaluated after $24 \mathrm{~h}$. The fatty acids were extracted from the enterocytes as previously described (12). After extraction and saponification (13), the fatty acids were derivatized with 4-bromomethyl7-coumarin (14) and the analysis was performed in a Shimadzu model LC-10A liquid chromatographer. The samples were eluted using a C8 column $(25 \times 4.6 \mathrm{~cm}$ ID, $5-\mu \mathrm{m}$ particles $)$ with a $\mathrm{C} 8$ pre-column $(2.5 \times 4.6$ $\mathrm{cm}$ ID, $5-\mu \mathrm{m}$ particles), at a flow rate of $1 \mathrm{ml} /$ min of acetonitrile/water $(77: 23, \mathrm{v} / \mathrm{v})$ and fluorescence detector (325 nm excitation and $395 \mathrm{~nm}$ emission) (13). The fatty acids used as standards were obtained from Sigma: lauric (C12:0), myristic (C14:0), palmitic (C16:0), palmitoleic (C16:1 $\omega 6)$, stearic (C18:0), oleic (C18:1 $\omega 9)$, linoleic (C18:2 $\omega 6)$, linolenic (C18:3 $\omega 6)$, arachidonic (C20:4), eicosapentaenoic (C20:5 $\omega 3$ ), docosahexaenoic (C22:6 13$)$, and margaric (C17:0) acids. The last fatty acid was used to calculate recovery and quantify the others. We constructed a calibration curve for each fatty acid standard, obtaining coefficients of correlation and regression. For quantification of fatty acids, the capacity factor $\left(K^{\prime}\right)$, elution sequence, linearity, recovery, precision, interference and limit of detection were determined. The minimum limit of quantification of the fatty acids ranged from 1 to $10 \mathrm{ng}$.

The unsaturation index of the fatty acids present in enterocytes was calculated as previously described $(15,16)$. Briefly, the proportion of each fatty acid multiplied by the number of double bonds present in the molecule was summed and the values are presented in Table 1. The polyunsaturated/saturated $(\mathrm{P} / \mathrm{S})$ fatty acid ratio of the total fatty acids present in enterocytes was calculated as previously described (17). The effect of cholesterol was analyzed statistically by ANOVA followed by the Tukey-Kramer test for comparison with control conditions (ethanol addition). The results are reported as means \pm SEM.

The experimental procedure used in this study was approved by the Ethics Committee of the Institute of Biomedical Sciences, University of São Paulo.

Rat fetal enterocytes presented a consistently higher number of cells when cultured in the absence of FCS for all periods studied (Figure 1A). For the period between 24 and $72 \mathrm{~h}$ in culture, the number of cells was about $42 \%$ higher in the absence than in the presence of serum. These findings are compatible with the fact that intestinal epithelial cells actively proliferate in the intestinal lumen, which occurs in the absence of serum.

Cholesterol has been shown to reduce the proliferation of various cell types such as lymphocytes (18), fibroblasts (6), intestinal epithelial cells (10) and tumor cells (5). Therefore, the reduction in the number of

Table 1. Effect of cholesterol on the fatty acid composition of rat fetal enterocytes after $24 \mathrm{~h}$ in culture.

\begin{tabular}{lcccc}
\hline $\begin{array}{c}\text { Fatty } \\
\text { acids }\end{array}$ & $\begin{array}{c}\text { Without } \\
\text { 10\% FCS } \\
\text { and ethanol }\end{array}$ & $\begin{array}{c}\text { Without } \\
10 \% \text { FCS } \\
\text { and } 20 \mu \mathrm{M} \\
\text { cholesterol }\end{array}$ & $\begin{array}{c}\text { With 10\% FCS } \\
\text { and ethanol }\end{array}$ & $\begin{array}{c}\text { With } \\
10 \% \text { FCS } \\
\text { and } 20 \mu \mathrm{M} \\
\text { cholesterol }\end{array}$ \\
\hline 12:0 Lauric acid & $4.81 \pm 0.71$ & $5.33 \pm 0.17$ & $5.50 \pm 0.39$ & $7.81 \pm 0.51^{*}$ \\
14:0 Myristic acid & $5.17 \pm 0.28$ & $4.86 \pm 0.30$ & $4.74 \pm 0.25$ & $4.26 \pm 0.20$ \\
16:0 Palmitic acid & $26.42 \pm 1.30$ & $26.03 \pm 1.72$ & $27.07 \pm 0.42$ & $23.83 \pm 0.39^{*}$ \\
16:1 Palmitoleic acid & $3.24 \pm 0.60$ & $3.65 \pm 0.51$ & $3.36 \pm 0.63$ & $3.02 \pm 1.00$ \\
18:0 Stearic acid & $30.44 \pm 2.30$ & $30.54 \pm 1.66$ & $29.98 \pm 1.72$ & $23.93 \pm 1.43^{*}$ \\
18:1 Oleic acid & $11.93 \pm 1.18$ & $11.17 \pm 0.46$ & $11.14 \pm 0.80$ & $14.93 \pm 0.30^{*}$ \\
18:2 Linoleic acid & $12.09 \pm 1.33$ & $10.69 \pm 1.69$ & $11.31 \pm 0.69$ & $16.29 \pm 0.85^{*}$ \\
18:3 $\gamma$-Linolenic acid & $1.30 \pm 0.21$ & $1.10 \pm 0.20$ & $1.17 \pm 0.04$ & $1.40 \pm 0.07^{*}$ \\
20:4 Arachidonic acid & $2.38 \pm 0.49$ & $4.48 \pm 0.52^{*}$ & $3.53 \pm 0.59$ & $2.79 \pm 0.93^{*}$ \\
20:5 EPA & $1.15 \pm 0.17$ & $0.85 \pm 0.07$ & $0.98 \pm 0.07$ & $1.06 \pm 0.06$ \\
22:6 DHA & $1.07 \pm 0.15$ & $1.30 \pm 0.13$ & $1.22 \pm 0.09$ & $0.68 \pm 0.04^{*}$ \\
P/S ratio & 0.49 & 0.48 & 0.48 & 0.67 \\
Unsaturation index & 64.45 & 69.60 & 67.12 & 75.30 \\
\hline
\end{tabular}

The cells $\left(10^{6}\right)$ were cultured in HF12 medium in the presence and absence of $10 \%$ fetal calf serum (FCS). The values are reported as means \pm SEM of eight samples from three experiments. P/S, polyunsaturated/saturated ratio; DHA, docosahexaenoic acid; EPA, eicosapentaenoic acid.

${ }^{*} \mathrm{P}<0.05$ compared to no cholesterol addition (ANOVA followed by Tukey-Kramer test). 
cells (Figure 1) may result from a low proliferative activity of the enterocytes as reported for the other cells. In the absence of serum, cholesterol reduced the number of cells by $41 \%$ after 6 and $12 \mathrm{~h}$ in culture. This effect of cholesterol was less pronounced in the presence of serum for both $6(26 \%)$ and $12 \mathrm{~h}$ $(29 \%)$. Thus, free cholesterol in the intestinal lumen may play a role in the control of epithelial cell proliferation.

The fatty acid composition of enterocytes cultivated in the absence of serum was only slightly changed by cholesterol (Table

Figure 1. A, Effect of $10 \%$ fetal calf serum (FCS) on the growth curve of rat fetal enterocytes cultivated in HF12 medium. B, Effect of cholesterol $(20 \mu \mathrm{M})$ and FCS on the total number of rat fetal enterocytes after 6 and 12 $h$ in culture. Data are reported as means \pm SEM of nine determinations from three cell preparations. ${ }^{*} \mathrm{P}<0.05$ compared to no cholesterol addition (ANOVA followed by Tukey-Kramer test).

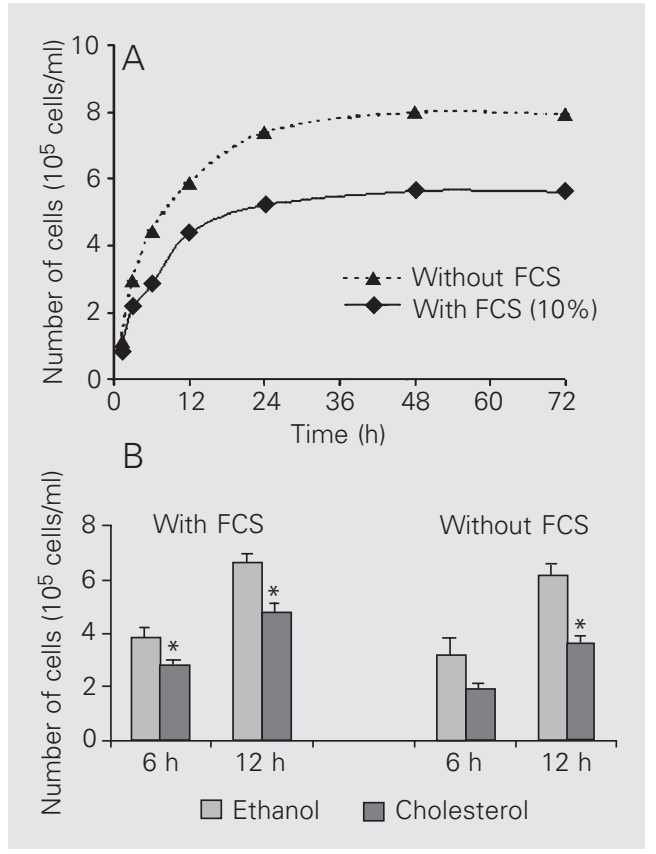

1). This sterol raised the proportion of arachidonic acid by $88 \%$, whereas the unsaturation index was increased from 64.45 to 69.60 .

On the other hand, there was a marked effect of cholesterol on the fatty acid composition of cells cultivated in the presence of serum. Cholesterol $(20 \mu \mathrm{M})$ increased the proportion of lauric (by $42 \%$ ), oleic (by $34 \%$ ), linoleic (by 44\%) and $\gamma$-linolenic (by 20\%) acids and reduced that of palmitic (by 12\%), stearic (by 20\%), arachidonic (by 21\%) and docosahexaenoic (by 44\%) acids. In addition to the changes in individual fatty acids, cholesterol increased the $\mathrm{P} / \mathrm{S}$ ratio (from 0.48 to 0.67 ) and the unsaturation index (from 67.12 to 75.30 ). Therefore, cholesterol treatment in the presence of serum (that mimics the conditions on the basolateral side of the intestinal epithelium) causes significant changes in fatty acid composition.

The present report is the first evidence that cholesterol modulates fatty acid composition of membranes possibly via de novo fatty acid synthesis and desaturation. These effects may be important for the function of the intestinal epithelium.

\section{Acknowledgments}

The authors are indebted to J.R. Mendonça and G. de Souza for technical assistance.

\section{References}

1. Oliveira HC, Nilausen K, Meinertz H \& Quintão EC (1993). Cholesteryl esters in lymph chylomicrons: contribution from high density lipoprotein transferred from plasma into intestinal lymph. Journal of Lipid Research, 34: 1729-1736.

2. Bosner SM, Lange LG, Stenson WF \& Ostlund RE (1999). Percent cholesterol absorption in normal women and men quantified with dual stable isotopic tracers and negative ion mass spectrometry. Journal of Lipid Research, 40: 302-308.

3. Quintão E, Grundy SM \& Ahrens Jr EH (1971). Effects of dietary cholesterol on the regulation of total body cholesterol in man. Journal of Lipid Research, 12: 233-247.

4. MacDonald IA, Bokkenheuser VD, Winter J, McLernon AM \& Mosbach EH (1983). Degradation of steroids in the human gut. Journal of Lipid Research, 24: 675-700.
5. Lescano-de-Souza Jr A \& Curi R (1999). Cholesterol inhibits glutamine metabolism in LLCWRC256 tumour cells but does not affect it in lymphocytes: possible implication for tumour cell proliferation. Cell Biochemistry and Function, 17: 223-228.

6. Brown MS \& Goldstein JL (1980). Multivalent feedback regulation of HMG-CoA reductase, a control mechanism coordinating isoprenoid synthesis and cell growth. Journal of Lipid Research, 21: 505-517.

7. Brown MS \& Goldstein JL (1997). The SREBP pathway regulation of cholesterol metabolism by proteolysis of a membrane-bound transcription factor. Cell, 89: 331-340.

8. Horton JD \& Shimomura I (1999). Sterol regulatory element binding proteins: activators of cholesterol and fatty acid biosynthesis. Current Opinion in Lipidology, 10: 143-150.

9. Field FJ, Born E, Murthy S \& Mathur SN (2001). Gene expression of 
sterol regulatory element-binding proteins in hamster small intestine. Journal of Lipid Research, 42: 1-8.

10. Fukamachi $H$ (1992). Proliferation and differentiation of fetal rat intestinal epithelial cells in primary serum-free culture. Journal of Cell Science, 103: 511-519.

11. Evans GS, Flint N, Somers AS, Eyden B \& Potten CS (1992). The development of a method for the preparation of rat intestinal epithelial cell primary cultures. Journal of Cell Science, 101: 219-231.

12. Folch J, Lee M \& Stanley GHA (1957). A simple method for isolation and purification of total lipid from animal tissue. Journal of Biological Chemistry, 226: 497-503.

13. Nishiyama-Naruke $A$, de Sousa JAA, Carnelós Filho $M$ \& Curi $R$ (1998). HPLC determination of underivatized fatty acid saponified at low temperature. Analysis of fatty acids in oils and tissues. Analytical Letters, 31: 2565-2576.

14. Abushufa R, Reed P \& Weinkove C (1994). Fatty acids in erythrocytes measured by isocratic HPLC. Clinical Chemistry, 40: 1707-
1712.

15. Moreira NX, Curi R, Padovese R \& Mancini-Filho J (2001). Incorporation of dietary trans mono-unsaturated fatty acids into tissues of Walker 256 tumor-bearing rats. Brazilian Journal of Medical and Biological Research, 34: 501-508.

16. Miyasaka CK, Mendonça JR, Nishiyama A, Alves de Souza JA, Pires de Melo M, Pithon-Curi TC \& Curi R (2001). Comparative effects of fish oil by gavage and fish oil-enriched diet on leukocytes. Life Sciences, 69: 1739-1751.

17. Guimarães ARP, Costa Rosa LFBP, Sitnik RH \& Curi R (1991). Effect of polyunsaturated (PUFA $n-6$ ) and saturated fatty acid-rich diets on macrophage metabolism and function. Biochemistry International, 23: $533-543$.

18. Homem de Bittencourt Jr PI \& Curi R (1998). Transfer of cholesterol from macrophages to lymphocytes in culture. Biochemistry and Molecular Biology International, 44: 347-362. 


\section{YOU SHALL WANT TO BROWSE IT EVEN IF YOU CANNOT READ PORTUGUESE}

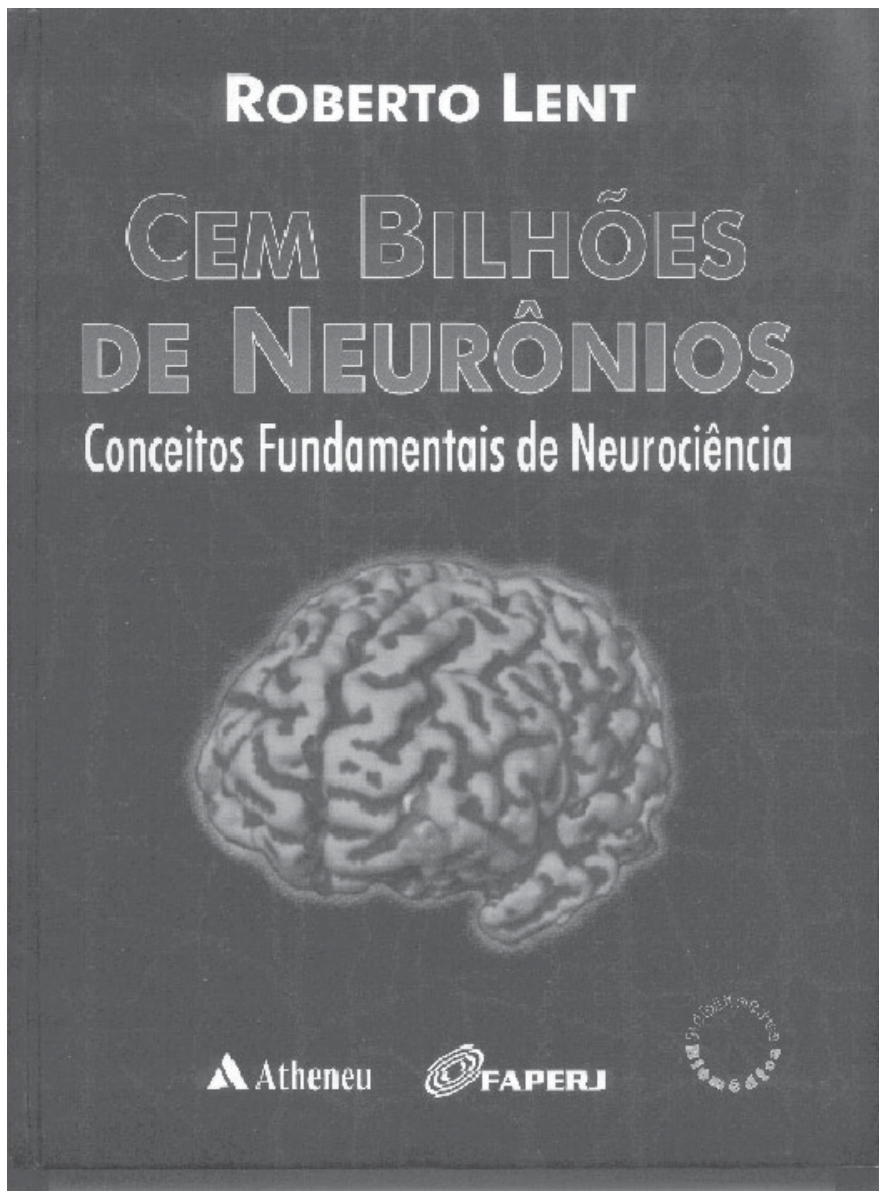

A complete textbook on the basic concepts of modern Neuroscience, featuring 20 chapters with about 400 colour illustrations, 30 boxes on the state-of-the-art of Neuroscience research written by Brazilian neuroscientists, and 20 boxes on the History of Neuroscience.

ORDER NOW:

\section{Editora Atheneu}

São Paulo: R. Jesuíno Pascoal 30, Santa Cecilia, CEP 01224-050, Phone: +55-11-222-4199 Rio de Janeiro: R. Bambina 74, Lis. A e B (21), CEP 22251-050, Phone: +55-21-2539-1295 